\title{
Uso de tecnologias digitais para \\ o Ensino a Distância da compreensão \\ e produção oral em língua inglesa por computador/WEB
}

\section{Digital Technology Use for Distance Education for Teaching Oral Comprehension and Production in English Mediated by Computer/Web}

Samuel de Carvalho Lima*

Instituto Federal de Educação, Ciência e Tecnologia

Mossoró - Rio Grande do Norte / Brasil

RESUMO: Considerando o recente panorama de pesquisas que refletem a relação e o compromisso da Linguística Aplicada (LA) com os fenômenos que envolvem o uso das relativamente novas Tecnologias de Informação e Comunicação (TIC), este trabalho propóe investigar propostas de atividades on-line para a oferta de ensino da compreensão e produção oral em língua inglesa como língua estrangeira mediado por computador/web, tendo em vista o uso das tecnologias digitais que medeiam a realização do ensino. $\mathrm{O}$ tratamento dos dados suscitou a elaboração do catálogo de uso e frequência das tecnologias em que os exemplares das propostas de atividades on-line se encontravam ancorados, o que expressa a forma como os educadores integram os recursos digitais em suas práticas pedagógicas.

PALAVRAS-CHAVE: proposta de atividade on-line; $\mathrm{EaD}$; língua estrangeira.

ABSTRACT: Considering the recent landscape of researches that reflect Applied Linguistics (AL) relation and commitment to phenomena that involve the use of relatively new Information and Communication Technology (ICT), this paper develops a study of online proposed activities to the offer of teaching oral comprehension and production in English as a foreign language mediated by the computer/web, in view of the digital technology uses that mediate teaching realization. Data analysis raised the elaboration of the catalog of technology use and frequency, in which the online proposed activity exemplars were anchored, and which expresses how educators integrate digital resources into their teaching practices. KEYWORDS: Online proposed activity; DE; foreign language.

* samuel.lima@ifrn.edu.br 


\section{Considerações iniciais}

Os estudos que contemplam a interface linguagem e tecnologia têm se demonstrado tão produtivos que, no Brasil, a Associação Nacional de PósGraduação e Pesquisa em Letras e Linguística (ANPOLL) inaugurou, em 2010, o grupo de trabalho (GT) Linguagem e Tecnologias, coordenado em seu primeiro biênio pelos professores doutores Vera Lúcia Menezes de Oliveira e Paiva, da Universidade Federal de Minas Gerais (UFMG), e Júlio César Araújo, da Universidade Federal do Ceará (UFC). O objetivo descrito no plano de trabalho do GT confirma a expansão e a recentidade das investigações que buscam elucidar os fenômenos emergentes dos usos das tecnologias em nossa sociedade, a saber: "fazer um levantamento histórico das pesquisas produzidas no Brasil envolvendo Práticas sociais da linguagem mediada pela tecnologia e traçar um panorama do estado da arte em termos de temas e de metodologia de pesquisa" (grifo dos autores). ${ }^{1}$

Fica evidente que a LA está comprometida com a elucidação de fenômenos que podem ser investigados a partir da observação das práticas sociais realizadas através do uso da tecnologia, sobretudo as Tecnologias de Informação e Comunicação (TIC), devido à contemporaneidade e à expansão do uso dessas tecnologias. Nesse contexto, a interação entre sujeito e tecnologia digital ora reflete práticas já previamente realizadas em um contexto off-line (SNYDER, 2009), migrando de situações presenciais para os ambientes virtuais (SILVA, 2008; PEREIRA; ARAÚJO, 2010; LIMA; ARAÚJO, 2011), ora emerge do próprio contexto virtual, necessária devido à natureza on-line e em rede das páginas da web. Em ambos os casos, as práticas sociais de linguagem estão sendo mediadas pelas TIC e concretizadas, por exemplo, através do uso de e-mail, das redes sociais, do internet banking, do Ambiente Virtual de Aprendizagem (AVA) etc., e a LA não poderia ignorar essa nova conformação social, pois, segundo salienta Moita Lopes (1996, p. 4), a LA tende a "privilegiar as relaçôes entre a ação humana e os processos de uso da linguagem", inclusive os usos mediados pelo computador. ${ }^{2}$

\footnotetext{
${ }^{1}$ O plano de trabalho do GT encontra-se disponível, na íntegra, no site da ANPOLL que hospeda as informaçôes do grupo Linguagem e Tecnologias: <http:// www.anpoll.org.br/portal/gts/\#>.

${ }^{2}$ Vale destacar o fato de que, quando menciono o computador, faço referência às suas possibilidades de interatividade de quando o utilizamos conectado à internet/ web. Quando eu precisar mencionar a limitação de um computador sem acesso à web, essa informação será salientada.
} 
Particularizando um pouco a conjuntura apresentada anteriormente e levando em consideração apenas as práticas sociais mediadas pelas TIC em contextos educacionais, Lankshear, Snyder e Green (2000) salientam o fato de que muitos educadores estão tendo de encontrar um modo para atender às demandas de um mundo mediado pelas TIC, pois descobrir uma maneira de integrá-las em suas práticas pedagógicas em uma forma significativa se torna pertinente ao compromisso com a formação de um cidadão mais participativo na sociedade em que atua. Sendo assim, neste trabalho, busco responder à seguinte indagação, norteadora da pesquisa ora empreendida: como os recursos digitais estão envolvidos nas propostas de atividades on-line de modo a contemplar a oferta do ensino da compreensão e produção oral em língua inglesa a distância?

Tendo em vista o questionamento anterior, meu objetivo neste trabalho ${ }^{3}$ consiste em descrever os usos da tecnologia que refletem a oferta do ensino a distância no curso semipresencial ${ }^{4}$ Letras/Inglês, realizado através do Solar, Ambiente Virtual de Aprendizagem (AVA) da Universidade Federal do Ceará (UFC), em parceria com a Coordenação de Aperfeiçoamento de Pessoal de Nível Superior e a Universidade Aberta do Brasil (CAPES/UAB). Desse modo, foi realizada a listagem dos recursos digitais em que os exemplares das propostas de atividades on-line se encontravam ancorados, de modo a fazer, também, o levantamento da frequência com que essas ferramentas eram utilizadas.

Ressalto que o resultado dessa elaboração pode servir de objeto para reflexão sobre a compreensão, o planejamento, a seleção e a elaboração dos conteúdos publicados em AVA para a realização do ensino de língua estrangeira a distância, o que, também, reflete concepçôes de ensino e de língua constitutivos do fazer pedagógico em contexto digital.

\footnotetext{
${ }^{3}$ Trabalho resultante da pesquisa de doutorado intitulada Ensino de linguas mediado por computador: um estudo das propostas de atividades online para o ensino da compreensão e produção oral em língua inglesa, orientada pelo Prof. Dr. Júlio César Araújo, do Programa de Pós-Graduação em Linguística (PPGL) da Universidade Federal do Ceará. O presente trabalho foi realizado com apoio do Conselho Nacional de Desenvolvimento Científico e Tecnológico - Brasil (CNPq).

${ }^{4}$ Entende-se por educação a distância $(\mathrm{EaD})$ semipresencial a oferta que mescla o ensino realizado através de encontros presenciais e o ensino realizado a distância. No âmbito da UFC Virtual, a EaD semipresencial é realizada de modo que $20 \%$ da carga horária dos cursos ofertados é ministrada presencialmente, e os $80 \%$ restantes são ministrados a distância, através do uso do Solar, AVA da instituição.
} 


\section{Fundamentação teórica}

Neste trabalho, os usos das tecnologias digitais para o ensino da compreensão e produção oral em língua inglesa estão relacionados à oferta de propostas de atividades on-line que são publicadas no Solar, AVA próprio da UFC para a realização dos cursos de graduação (licenciatura/bacharelado) semipresenciais dessa universidade. Em relação à literatura concernente à proposta de atividade on-line, encontramos sinalizaçôes para uma autora que cunhou a expressão atividade eletrônica em língua inglesa, e-tivity. Salmon (2002, p. 1), portanto, é responsável pela compreensão do conceito de atividade eletrônica, restringindo-a à oferta que, em potencial, permite o desenvolvimento de uma aprendizagem ativa e interativa através de propostas de atividades on-line ofertadas em ambientes virtuais. Levando em consideração a definição dada pela própria autora para a expressão $e$-tivity, tomo a decisão de me referir a essa concepção através da expressão de que venho fazendo uso até o presente momento, proposta de atividade on-line, pela razão de atribuir uniformidade ao meu texto.

A independência das propostas de atividades on-line em relação aos demais conteúdos que podem ser encontrados no contexto de ensino de línguas a distância é algo que já destaquei, também em parceria com colegas, em trabalhos anteriores (LIMA, 2009; LIMA, 2010a; 2010b; 2010c; LIMA; ARAÚJO, 2010; LIMA, 2011; ARAÚJO; LIMA, 2011; LIMA; ARAÚJO; DIEB, 2011). Essas propostas são responsáveis, em grande parte, pela avaliação do conhecimento dos alunos. Dessa forma, elas podem representar uma autoavaliação que é feita pelo próprio aluno, quando oferecem respostas automáticas às suas demandas (preenchimento de lacunas, perguntas etc.), para que sejam corrigidas pelo aluno; ou podem representar uma avaliação por pares, quando monitoradas e analisadas por tutores/professores, através da observação ou do seu recebimento após envio ou publicação pelos alunos.

$\mathrm{Na} \mathrm{EaD}$ semipresencial, as propostas de atividades on-line são ancoradas em recursos digitais responsáveis pela mediação dos conhecimentos que são trabalhados no período do curso que é realizado a distância. Sendo assim, propostas de atividades on-line e tecnologias devem dar conta, inclusive, da ausência da interação social face a face entre os participantes do processo de ensino-aprendizagem, apresentando aos alunos opçōes em relação aos caminhos mais adequados às necessidades individuais, bem como podem contrastar informações conflitantes ou complementares, proposta 
fundamental para o desenvolvimento de uma aprendizagem analítica e reflexiva (BRAGA; COSTA, 2000).

Em relação à compreensão e produção oral de língua inglesa como língua estrangeira, Harmer $(1998$; 2001) e Brown (2000) discutem princípios básicos que devem ser levados em consideração para a realização da oferta de ensino. Entre eles, podemos apontar: os alunos devem ser encorajados a compreender o conteúdo, não apenas a gramática, de modo a relacionar forma e função; o vídeo pode ser considerado um instrumento mais caro ao processo de ensino-aprendizagem, pois os falantes podem ser vistos; a realização da compreensão oral interativa deve ser encorajada; o uso de linguagem autêntica em contextos significativos deve ser encorajado; etc.

Leffa (2008) traz para discussão a diferença entre teoria e prática constitutivas da oferta de propostas de atividades no ensino de língua estrangeira. Na prática, existe a fragmentação, a busca por discriminar e classificar, a oferta de uma quantidade numerosa de propostas de atividades especializadas para atender a objetivos bem específicos. Valendo-se da metáfora seguinte, o autor avalia que "o aluno é visto como uma garrafa de gargalo estreito, de modo que a aprendizagem só ocorre se o conteúdo for colocado aos poucos, a conta-gotas" (LEFFA, 2008, p. 142). As propostas de atividades para o ensino de língua estrangeira, portanto, não orientariam para o desenvolvimento da língua como um todo, mas, sim, para segmentos que, isolados, refletindo habilidades muito específicas, dificilmente oportunizariam o desenvolvimento de habilidades comunicativas maiores. Essas propostas de atividades facultariam, mais particularmente, a memorização de palavras, sem a possibilidade de construção de frases; a elaboração de frases, sem a possibilidade de uso da língua em contextos reais; a ausência, portanto, de uso autêntico. Para o autor, é essa prática que reflete o uso de propostas de atividades que orientam a fragmentar segmentos menores até o nível do fonema, através da repetição de pares mínimos; da busca pelo automatismo, realizado do nível lexical ao pragmático; da repetição e manipulação de segmentos linguísticos, quanto à afirmação, negação e interrogação. Seria essa a prática realizada pelos responsáveis pela oferta de ensino de língua inglesa a distância, tendo em vista que os mesmos podem contar com os recursos digitais e a interatividade em potencial para a mediação dos conteúdos de forma mais significativa e próxima aos usos reais da língua estrangeira?

Para termos uma melhor compreensão sobre a relação entre ensino de línguas e tecnologia, é importante reforçar que, no Brasil, devido às enormes 
diferenças sociais, em alguns lugares nem mesmo as tecnologias básicas como o papel, o livro e a eletricidade podem ser utilizadas, em virtude da carência presente em determinadas comunidades. Além disso, "muitas tecnologias já obsoletas, como o projetor de slides, por exemplo, nunca chegaram a determinadas escolas" (PAIVA, no prelo, p. 14). No escopo deste trabalho, a análise realizada trata dos recursos digitais do Solar, AVA para a oferta dos cursos de graduação semipresencial da UFC. Para Paiva (2010, p. 357), os ambientes virtuais de aprendizagem "oferecem espaços virtuais ideais para que os alunos possam se reunir, compartilhar, colaborar e aprender junto", como resultado da necessidade do gerenciamento de propostas pedagógicas que se utilizam das potencialidades de interatividades da web. A seguir, portanto, apresento o percurso metodológico trilhado para a elaboração do catálogo dos usos das tecnologias digitais para a compreensão e produção oral em língua inglesa a distância.

\section{Metodologia}

Em função do objetivo geral de estudar as propostas de atividades online para o ensino da compreensão e produção oral em língua inglesa por computador/web, tendo em vista os usos das tecnologias digitais que permeiam essa oferta, desenvolvi uma pesquisa qualitativa, de cunho predominantemente exploratório (RAUPP; BEUREN, 2004). Sendo assim, descrevo o ensino da compreensão e produção oral da graduação Letras/Inglês da UFC, levando em consideração os recursos digitais utilizados para a realização da oferta das propostas de atividades on-line presentes no material didático hospedado no Solar.

Para que os procedimentos da coleta do corpus sejam evidenciados, fazse necessário, anteriormente, apresentar uma breve contextualização sobre o universo investigado. A UFC, por meio de sua unidade acadêmica Instituto UFC Virtual, em parceria com a CAPES/UAB, oferta cursos de graduação semipresencial servindo-se dos recursos de um AVA próprio, chamado Solar. Essa parceria visa ao desenvolvimento de um conjunto integrado de ferramentas dedicadas à construção de um ambiente educacional virtual, cooperativo e colaborativo, baseado na ampla interatividade e no compartilhamento de recursos, potencializando o acesso ao ensino de qualidade, sendo uma via aberta para a democratização do saber e representando um programa nacional que propicia ganhos, não só em termos de regiốes 
geográficas, ${ }^{5}$ mas também de quantidade e velocidade de aprendizagem, conforme apresentado no Portal da UFC Virtual. ${ }^{6}$

Considerando-se o universo descrito anteriormente, na graduação semipresencial Letras/Inglês, encontramos disciplinas cujo objetivo é garantir o ensino da compreensão e produção oral em língua inglesa. São elas:

- Língua Inglesa IA: compreensão e produção oral;

- Língua Inglesa IIA: compreensão e produção oral;

- Língua Inglesa IIIA: compreensão e produção oral;

- Língua Inglesa IVA: compreensão e produção oral;

- Língua Inglesa VA: compreensão e produção oral.

Como os títulos evidenciam, essas disciplinas visam ao desenvolvimento do ensino da compreensão e produção oral em língua inglesa de forma contínua, em cinco semestres, diferenciando-se apenas no nível em que serão trabalhadas essas habilidades, do inicial ao avançado, o que reflete a continuidade do processo. Considerei, portanto, que, ao contemplar, exclusivamente, a primeira aula (Aula 1) da disciplina Língua Inglesa IA: Compreensão e Produção Oral e a última aula (Aula 5) da disciplina Língua Inglesa VA: Compreensão e Produção Oral, o corpus pudesse ser constituído das propostas de atividades on-line que evidenciassem esse processo de ensino, resultando em 41 propostas de atividades on-line praticadas nessas duas aulas.

Para a realização da análise, listei a tecnologia digital em que os exemplares das propostas de atividades on-line se encontravam ancorados, de modo a fazer, também, o levantamento da frequência com que essas ferramentas eram utilizadas. O gráfico resultante desse levantamento representa o catálogo das tecnologias digitais utilizadas pelos elaboradores do material

\footnotetext{
${ }^{5} \mathrm{O}$ curso Licenciatura em Letras/Inglês é ofertado nas seguintes cidades do estado do Ceará: Aracati, Beberibe, Brejo Santo, Caucaia, Itapipoca, Maranguape, Meruoca, Piquet Carneiro, Quiterianópolis e Quixadá.

${ }^{6}$ Vale salientar que essa se trata da perspectiva da instituição, da função explícita da universidade. Em termos de um funcionamento implícito, as políticas públicas de investimento em $\mathrm{EaD}$ têm interesse não apenas na expansão, mas também na diminuição de custos, considerando-se a diferença entre recursos gastos em uma unidade presencial e em uma unidade a distância, por exemplo.
} 
didático para o ensino da compreensão e produção oral em inglês por computador. Essa elaboração encontrou motivações em Lankshear, Snyder e Green (2000), que questionam a forma como os educadores integram os recursos digitais em suas práticas pedagógicas de modo a refletir uma proposta de ensino comprometida com a formação do cidadão que vive em uma sociedade em que as práticas sociais são mediadas pelas TIC. Através de exemplificaçôes, discuti as implicações dos usos dos recursos digitais para o estabelecimento dessa oferta de ensino, em função da reflexão sobre as possibilidades de ensinar tendo em vista o uso significativo da tecnologia utilizada e sua pertinência no contexto de ensino-aprendizagem.

Para isso, os procedimentos de fragmentação, compreensão e associação também foram atualizados, tendo em vista que a categorização resulta da interpretação das informaçōes emergentes dos próprios dados presentes nos enunciados das propostas de atividades on-line, verificados no texto verbal escrito. Expressōes do tipo click on the links below, listen to their definition, ${ }^{8}$ record your readings and upload your audio file to your portfolio listen to three conversations, ${ }^{10}$ listen to the video below ${ }^{11}$ etc. foram importantes de serem percebidas, pois elas apontam, em primeiro lugar, para o esforço do elaborador do material didático de utilizar ao máximo os recursos digitais disponíveis pelo ambiente digital. Em segundo lugar, elas sinalizam para a tecnologia em que a proposta de atividade on-line se encontra ancorada, o que nos permite recuperar, ainda, vários gestos de leitura e escrita: ler o texto em voz alta; selecionar uma tecnologia para poder gravar o áudio dessa leitura; depois fazer o upload desse arquivo digital em uma ferramenta específica do AVA. Segue o gráfico que reflete a listagem da tecnologia digital utilizada, relacionando-a com o valor numérico que representa a frequência com que a tecnologia se demonstrou constitutiva da proposta de atividade on-line. A discussão sobre esses usos é reservada para o próximo capítulo, de resultados e discussão.

\footnotetext{
7 "clique nos links abaixo".

8 "escute suas definiçôes".

9 "grave sua leitura e poste seu áudio em seu portfólio".

10 "escute três conversas".

11 "escute o vídeo abaixo".
} 


\section{Recurso digital e frequência de utilização}

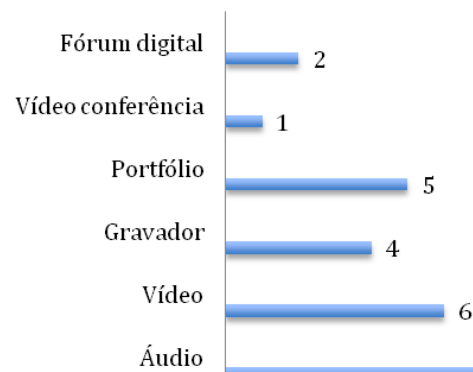

Áudio

GRÁFICO 1 - Recurso digital e frequência de utilização

Fonte: LIMA, 2012, p. 76.

\section{Resultados e discussão}

Tendo em vista a oferta do ensino da compreensão e produção oral em língua inglesa por computador/web e suas relações com as possibilidades de usos da interatividade da web, através de suas ferramentas digitais, listei os recursos digitais utilizados nas propostas de atividades on-line: o áudio, ${ }^{12} \mathrm{o}$ vídeo, o gravador, o portfólio, a videoconferência e o fórum eletrônico (ou digital). Segue, a seguir, o gráfico que ilustra a frequência de uso do recurso digital constitutivo da proposta de atividade on-line para o ensino da compreensão e produção oral em língua inglesa:

\footnotetext{
${ }_{12}$ Entende-se por áudio o arquivo composto predominantemente por som e que possibilita sua contemplação através, exclusivamente, da interação entre a audição humana e os recursos tecnológicos que possibilitam a emissão dos sons gravados nele (de palavras, frases, diálogos etc.).
} 


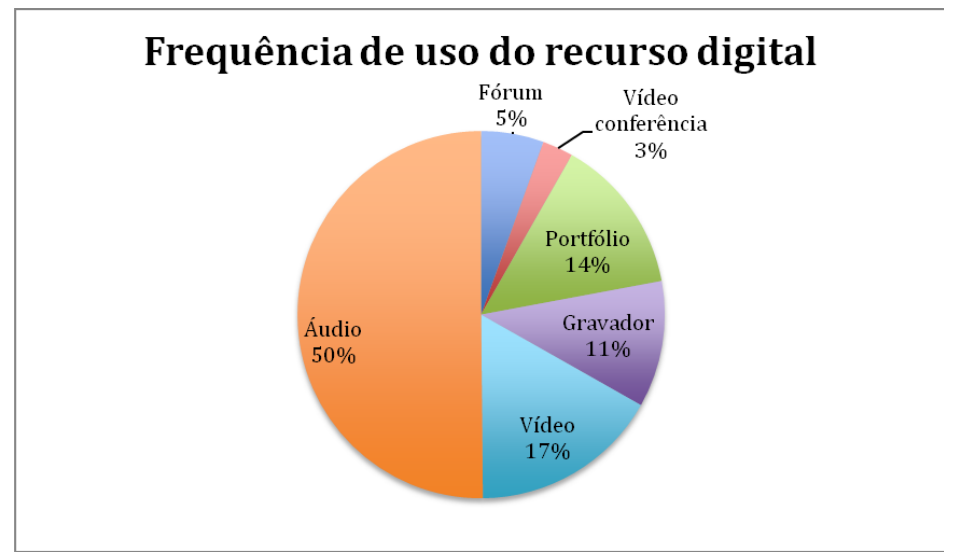

GRÁFICO 2 - Frequência de uso do recurso digital Fonte: LIMA, 2012, p. 112.

Como podemos observar, coerente com a proposta de uma oferta de ensino a distância que busca desenvolver, nos alunos, predominantemente, as habilidades de fala e escuta, o áudio foi o recurso que se demonstrou mais frequente, estando relacionado a dezoito das 41 propostas de atividades on-line analisadas. Em se tratando da responsabilidade para promover a interação e a comunicação, pude perceber que esse tipo de oferta demonstrou um certo padrão que resulta em duas formas de como o recurso digital áudio, envolvido na proposta de atividade on-line, relaciona-se à promoção do ensino a distância das habilidades orais. Em uma dessas formas, fica evidente que a interação com texto escrito, a compreensão oral de informações específicas e a compreensão oral de detalhes estão predominantemente relacionadas a esse tipo de oferta. Vejamos um exemplo dessas relaçóes:

\section{Exemplo 1}

"Listening to computer words. Listen to the text and complete the blanks: The computer mouse celebrated its $40^{\text {th }}$ anniversary on December the $8^{\text {th }}$. It was in 1968 that computer visionary Douglas Engelbart showed off his new invention to an audience of 1,000 at a $[\ldots]$ Click here and check your answers $[\ldots] "{ }^{13}$

13 "Escutando palavras da computação. Escute o texto e preencha as lacunas: $\mathrm{O}$ mouse de computador celebrou seu quadragésimo aniversário no dia 8 de dezembro. Foi em 1968 que o visionário da computação Douglas Engelbart mostrou sua nova invenção para uma audiência de mil pessoas na [...] Clique aqui e confira suas respostas $[\ldots]$ ". 
Como é possível observar, a orientação da proposta de atividade on-line ilustrada no exemplo 1 solicita ao aluno que ele preencha as lacunas de um texto escrito com as informações ouvidas através do áudio que lhe é disponibilizado. Nesse caso, vale ressaltar que essa forma de trabalhar a compreensão oral pode acarretar a atualização de aspectos positivos listados por Harmer $(1998 ; 2001)$ quanto ao ensino dessa habilidade, principalmente a aprendizagem subconsciente, possível através da exposição à informação, à gramática, à pronúncia, ao ritmo, à entonação, ao timbre e à tonicidade, que, nesse caso, é resultante da interação com o áudio que oferece a leitura de um texto por parte de um nativo ou de uma pessoa fluente na língua inglesa. Além disso, a oferta da proposta de atividade on-line cujo recurso predominante é o áudio, imbricada com a interação com o texto escrito e a busca de informações específicas, acaba por distanciar as características dessa prática realizada a distância das características dessa mesma oferta quando ela é realizada em contextos presenciais, devido, principalmente, à confluência das mídias e das demandas relacionadas a esses contextos. O que quero dizer é que, caso essa mesma oferta fosse realizada em contextos presenciais, primeiramente o professor teria que portar tanto o dispositivo com o áudio gravado (CD, pendrive etc.) quanto o dispositivo para a reprodução do áudio (CD player etc.). Além disso, seria preciso oferecer aos alunos o texto escrito com o qual trabalhariam na intenção de preencher lacunas através da escuta do áudio. A possibilidade mais prática para a realização da proposta de atividade seria por meio da impressão gráfica, o que gera custo e gasto, além de, na contemporaneidade, poder ser considerada prática com implicaçôes ecológicas negativas. Projetar o texto em um datashow também poderia ser uma possibilidade, que, no entanto, acabaria por resultar em um recurso a mais que ficaria sob a responsabilidade do professor.

Ademais, a realização dessa oferta em contexto presencial, em sala de aula, ignora as individualidades relacionadas ao ritmo dos alunos (HARMER, 1998; 2001), uma vez que a forma da exposição do áudio é orientada pelo professor da mesma forma para todos os alunos: quantas vezes o áudio é repetido? Em que momentos pode haver pausas? Diferentemente dessa oferta mais uniformemente orientada quando atualizada em contextos presenciais, nos contextos de ensino-aprendizagem em ambientes virtuais, através das tecnologias digitais, parece poder haver uma oportunidade de otimização desse processo. Essa possibilidade se deve a uma interação ilimitada entre os alunos e o áudio, no sentido de que os alunos podem fazer uso do áudio quantas vezes 
forem necessárias para a realização das propostas de atividades, de acordo com o seu ritmo individual, realizando pausas e repetições personalizadas. Simultaneamente, os alunos interagem com o texto escrito com base em um mesmo suporte, o computador, que, por sua vez, ao atualizar as potencialidades de interatividade da web, possibilita a oferta do ensino da compreensão e produção oral dessa forma dinâmica, possibilitando, também, uma maior confluência entre as mídias envolvidas para a realização bem sucedida da proposta de atividade on-line.

Preciso destacar ainda que, obviamente, o planejamento pedagógico, para que isso possa ser realizado, não pode ser ignorado. Dessa forma, a criatividade dos professores responsáveis pela oferta do ensino da compreensão e produção oral em língua inglesa, juntamente com o compromisso de oportunizar essa oferta de uma forma dinâmica, atrativa para os alunos e mais significativa, são premissa para o planejamento da oferta de propostas de atividades on-line comprometido com os participantes envolvidos no processo de ensino-aprendizagem e com as nuances subjacentes à própria prática de se ensinar e aprender através das tecnologias digitais, uma vez que considera a atualização das potencialidades de interatividade desses recursos.

Diferentemente do exemplo 1, o exemplo a seguir ilustra a segunda forma do padrão encontrado de como o recurso digital áudio, envolvido na proposta de atividade on-line, relaciona-se à promoção do ensino a distância das habilidades orais. Vejamos a apresentação do exemplo 2 para que as relaçōes entre a forma como os recursos digitais são utilizados e a maneira como a oferta do ensino da compreensão e produção oral é realizada possam ficar mais evidentes:

Exemplo 2

"Kent is going to his classes with Melissa (his best friend) when he meets Angelica. Listen to the dialogue and repeat the sentences. Notice the way he introduces Melissa to Angelica [...]". ${ }^{14}$

Como podemos observar, a proposta de atividade anterior solicita ao aluno que escute um diálogo entre três personagens em um contexto informal de comunicação e repita as frases que são enunciadas por essas personagens,

\footnotetext{
14 "Kent está indo para aula com Melissa (sua melhor amiga) quando ele se encontra com Angelica. Escute o diálogo e repita as frases. Observe a maneira como Kent apresenta Melissa à Angelica [...]".
} 
atentando mais particularmente para a função sociocomunicativa de cumprimentar outras pessoas. Antes de deixar mais explícita minha decisão de interpretar esses dados de modo a compreender duas formas que refletem o padrão encontrado de como o recurso digital áudio, envolvido na proposta de atividade on-line, relaciona-se à promoção do ensino a distância das habilidades orais, é importante observar que as frases ditas durante o diálogo da proposta de atividade on-line ilustrada pelo exemplo 2 são apresentadas ao aluno na forma de texto escrito, o que permite, também, a prática da leitura.

Dito isso, cabe-nos refletir um pouco a respeito da decisão de se ter a oferta do ensino das habilidades orais em língua estrangeira, de compreensão e produção, pautada, predominantemente, na interação com o texto escrito. Por ser uma oferta a distância, o texto escrito necessariamente precisa ser a modalidade mediadora e oportunizadora da realização das interaçôes e, eventualmente, comunicação desenvolvidas pelos alunos? Penso que não, e prefiro acreditar que essa prática reflita apenas uma de outras variadas formas de concretização desse tipo de oferta de ensino.

Juntamente com Brown (2000b), acredito que seja quase impossível vislumbrar um contexto de ensino-aprendizagem que se sustente praticando apenas uma única habilidade linguístico-comunicativa independente das demais. Como se ensinar a produção escrita sem demandar habilidades para a realização da compreensão dessa mesma modalidade? Como trabalhar a fala sem sua contraparte, a audição? Sabemos que, nesse caso, o que está em jogo é o foco, a predominância, a prioridade, e não a exclusividade. No entanto, quando analisamos a proposta de atividade on-line ilustrada pelo exemplo 2, podemos perceber que, muito embora a interação com o texto escrito por parte do aluno seja inevitável, uma vez que sua configuração apresenta, por escrito, o diálogo disponibilizado pelo recurso de áudio, a relação áudio e interação com texto escrito pode não ser necessária para a prática da produção oral. O que quero dizer é que esse tipo de proposta de atividade on-line poderia privar o aluno da exposição por escrito do diálogo que deve ser ouvido e repetido pelo mesmo, sem prejuízos para o cumprimento e o alcance dos objetivos subjacentes à oferta dessa proposta de ensino.

Embora a tecnologia digital seja a mesma tanto no exemplo 1 quanto no exemplo 2, sua utilização cumpre propósitos distintos. No primeiro caso, ela encontra-se relacionada à interação com texto escrito, que sofre alterações a partir do preenchimento de lacunas, o que é possível apenas através da compreensão oral do áudio, mais particularmente através da prática de compreensão oral de 
informaçōes específicas e/ou de detalhes. No segundo caso, encontra-se mais comprometida à fomentação da prática de produção oral, muito embora subjacentemente compreendida, nesse caso, por repetição de frases constitutivas de um diálogo informal, não possibilitando o desenvolvimento de uma postura mais (cri)ativa e participativa por parte dos alunos.

Salvas as distinçôes entre esses dois tipos de oferta cuja ferramenta digital áudio é central, vale destacar que suas semelhanças a tornam bem aproximadas quando observamos a particularidade de que em ambos os casos a ausência de interação social se faz evidente. Como consequência, é possível chegar à conclusão de que a oferta de ensino da compreensão e produção oral em língua inglesa que estabelece relações intrínsecas com o recurso digital áudio se configura, predominantemente, a partir de traços da interação reativa (PRIMO, 2001), pois é responsável por um fluxo previsível a ser percorrido pelos alunos, além de apresentarem o disparo de informações predeterminadas e promoverem as associações de ação/reação e estímulo/resposta, refletindo, assim, uma perspectiva predominantemente da psicologia cognitiva para a língua e seu ensino.

Além disso, vale ponderar sobre os possíveis usos feitos com essa tecnologia digital de modo a procurar compreender seus usos como mediadores do processo de ensino-aprendizagem, pois podem refletir a compreensão de língua e ensino subjacente às escolhas feitas pelos proponentes desse tipo de atividade on-line que se encontra ancorada no recurso áudio e a sua relevância para o ensino de línguas. Muito embora as tecnologias que estão sendo levadas em consideração nesta investigação sejam de natureza digital, é possível observar que sua utilização, em alguns casos, remete-nos a tempos remotos. Conforme salienta Paiva (no prelo), em relação ao impacto do uso de tecnologias no ensino de línguas, temos destacado o ano de 1878, que celebra a invenção do fonógrafo (cilindro), seguido pelo gramofone, com gravação em discos e, posteriormente, pela fita magnética, cujo marco é datado em 1940, com a inovação tecnológica que resulta no produto gravador de fita magnética.

A relevância dessas tecnologias para o ensino de línguas reflete uma postura (teórico-metodológica) de ênfase na oralidade, através da imitação e da repetição de amostras de fala gravadas por nativos. Vale ponderar, portanto, que é possível que não encontremos muitas diferenças entre as posturas assumidas pelos responsáveis pela oferta de ensino da compreensão e produção oral em língua inglesa por computador, flagradas através do estudo das propostas de atividades on-line praticadas nesse contexto, situadas no século $\mathrm{XXI}$, comuns e pertinentes às demandas sociais e profissionais atuais, e a postura 
de oferta de ensino dessas habilidades em tempo e espaço remotos, em que uma perspectiva de abordagem comunicativa para o ensino de línguas ainda não protagonizava o debate e o elemento norteador dos comportamentos dos participantes desse processo.

Em proporção bem menor, a oferta das propostas de atividades on-line para o ensino da compreensão e produção oral em língua inglesa por computador que se ampara na tecnologia digital vídeo foi flagrada apenas em seis exemplares dos 41 dados coletados para esta investigação. Na configuração das propostas de atividades que se utilizam desse recurso, o vídeo se caracteriza como elemento com o qual a interação se faz necessária para que a realização bem-sucedida da proposta de atividade on-line possa acontecer. Da mesma forma que o áudio, nessa oferta de ensino a distância, o percurso realizado pelo aluno para o cumprimento das demandas apresentadas pela proposta de atividade on-line pode ser personalizado, no sentido de que, nas dimensões dos ambientes virtuais, o aluno decide, dentre as possibilidades oferecidas, a forma como realiza sua interação com a tecnologia digital, podendo proceder a pausas e repetiçóes de acordo com o (seu) ritmo individual. Vejamos um exemplar ilustrativo dessa oferta:

Exemplo 3

"Download the video about the Internet. Watch the video and answer the following questions. Watch carefully. History of the Internet. Write down the things we can do with the Internet according to the video [...] Click here and check your answers. Send emails, make calls through the Internet $[\ldots] " .{ }^{15}$

Como podemos observar, a realização da proposta de atividade on-line ilustrada pelo exemplo 3 se encontra ancorada na interação com o recurso digital vídeo, cujo download precisa ser feito pelo aluno para que ele possa assisti-lo e, em seguida, escrever uma síntese sobre o assunto abordado naquela mídia. Carente de uma orientação para a comunicação, essa proposta de atividade on-line se assemelha com a primeira forma apresentada como resultante do padrão que articula a oferta de ensino da compreensão e produção oral em língua inglesa com a tecnologia digital áudio. Desse modo, ficam

15 "Faça o download do vídeo sobre a internet. Assista ao vídeo e responda às seguintes questóes. Assista cuidadosamente. A História da Internet. Escreva as coisas que nós podemos fazer com a Internet de acordo com o vídeo [...] Clique aqui e confira suas respostas. Enviar e-mails, fazer ligaçôes através da internet [...]". 
salientes: a interação com o texto escrito, que reflete a síntese a ser produzida após o aluno ter assistido ao vídeo; e a compreensão oral de informações específicas e/ou detalhes, que compreende, nesse caso, recuperar as informações sobre o que é possível fazer com o uso da internet.

Embora essa aproximação seja evidente, é importante perceber que o vídeo pode ser considerado um instrumento mais estimado no processo de ensinoaprendizagem nesse contexto, pois, além de possibilitar o contato com a língua estrangeira, por parte dos alunos, de modo a atualizar seu uso levando em consideração as particularidades típicas da língua falada, tais como as repetiçóes, as hesitações, as omissões etc., é através do vídeo que os alunos podem visualizar os falantes dessa língua, nativos ou fluentes, bem como o movimento de seus corpos, as roupas que vestem e a localização em que se encontram, o que, em conjunto, transmite informações que contribuem para os significados que emergem da interação do aluno com essa tecnologia digital, ao fazerem uso de seu conhecimento prévio, ativado de forma visual (HARMER, 1998).

Outra tecnologia digital saliente nas propostas de atividades on-line é a videoconferência. Muito embora a videoconferência seja considerada uma ferramenta de uso previsto no contexto de ensino-aprendizagem através do AVA Solar, uma vez que ela está listada nos recursos que otimizam a interação social e a comunicação entre os participantes do processo, houve apenas uma única proposta de atividade on-line, apresentada em língua portuguesa mesmo, que pressupôs seu uso para o cumprimento dos objetivos subjacentes à oferta de ensino. Vejamos sua configuração, através da apresentação do exemplo 4:

Exemplo 4

"Ao final desta lição você participará de uma videoconferência com seu tutor e demais colegas de turma. O objetivo desta videoconferência é que você identifique colegas que tenham algum tipo de afinidade com você; por exemplo, alguém que seja da sua idade; ou alguém tenha o mesmo nome ou sobrenome que o seu, etc. Ao final do tempo da videoconferência, você dirá o que tem em comum com seus colegas [...]"

A web conferência permite que os sujeitos que a praticam não apenas se escutem mas também se vejam. De algum modo, essa natureza tecnológica do referido gênero parece simular uma conversa face a face, não pela escrita, como é comum por meio de chats educacionais, mas pela oralidade e por gestos corporais que são mobilizados on-line pelos sujeitos aprendizes. Esse gênero parece promover a ilusão da sala de aula presencial e isso, de repente, pode ser importante para os alunos que se motivarão para falar e ouvir. Esse cenário 
construído os obriga a serem desinibidos, a se arriscarem mais e a se exporem mais, muito embora ver os outros (e a si próprio) no vídeo possa ser fator de inibição nesse tipo de interação. Uma proposta de atividade on-line dessa natureza, portanto, parece ser adequada ao curso de graduação virtual que deseja, no caso da disciplina em questão, oportunizar situações didáticas por meio das quais os alunos possam praticar a produção e a compreensão oral da língua inglesa.

Muito embora seja possível observar a relevância da videoconferência nesse contexto, uma vez que ela possibilita maior participação e comunicação entre os participantes do processo de ensino-aprendizagem de língua estrangeira, através da emissão e visualização de vídeos de seus interlocutores, seu uso se demonstra tímido e escasso, o que parece nos levar a acreditar que há uma incoerência entre o que se acredita ser relevante para o desenvolvimento de um ensino significativo de língua, na teoria, e o que se realiza na prática (LEFFA, 2008). No entanto, essa baixa frequência de uso de tecnologias digitais que se apresentam como otimizadoras do processo de ensinoaprendizagem de línguas estrangeiras precisa ser ponderada, uma vez que ela não necessariamente precisa indicar essa incoerência entre teoria e prática. Primo (2001), por exemplo, evidencia que as demandas tecnológicas para a constituição da imagem videográfica somada ao áudio da voz do interlocutor acaba por resultar em uma enorme quantidade de dados computacionais que se constitui em um impedimento para o uso, devido à baixa taxa de transmissão de bits $^{16}$ por segundo na internet, reflexo da ainda pequena largura de banda da rede brasileira para o envio de dados em tempo real.

Devido a essa situação um tanto limitadora, é possível que a experiência com a videoconferência já tenha se demonstrado como resultante da oferta de um produto com qualidade comprometida, com imagens e sons truncados, e isso faça com que os proponentes da oferta do ensino da compreensão e produção oral em língua inglesa por computador optem por ancorar as propostas de atividades online elaboradas para serem hospedadas no Solar em outras ferramentas que demandem uma menor exigência de cunho tecnológico. Lamentavelmente, essa limitação também pode ter como consequência a ausência de propostas de atividades on-line que oportunizem a prática da compreensão e produção oral de maneira interativa, como defende Brown (2000b).

16 Bit é a abreviação da expressão dígito binário e representa a menor unidade de informação que pode ser armazenada ou transmitida, utilizada tanto na computação quanto na teoria da informação (<http://pt.wikipedia.org/wiki/Bit>). 
Nessa oferta de ensino, os alunos podem ser encorajados a participarem em discussōes, debates e conversações demonstrando uma postura ativa, baseados em uma interação preliminar com um áudio/vídeo específico, o que, consequentemente e, quase, automaticamente, leva à compreensão e produção oral em língua estrangeira de forma autêntica no processo da comunicação.

No contexto de ensino-aprendizagem em AVA em que a baixa taxa de transmissão de bits por segundo na internet se demonstra limitadora, o fórum eletrônico parece ser promissor, uma vez que se trata de uma ferramenta assíncrona em que há a predominância do uso do texto escrito para a realização das orientaçōes que se encontram nas propostas de atividades on-line, o que, por sua vez, apresenta baixa demanda do aparato tecnológico e das características de velocidade de transmissão de dados pela internet, constituindo-se, ainda, em um gênero de discurso pertinente no contexto de ensino-aprendizagem de língua estrangeira, conforme discutido na subseção anterior. No entanto, assim como no caso do uso da videoconferência, o recurso digital fórum eletrônico também apresentou uma baixa frequência no que concerne à utilização, prevista nas orientações das propostas de atividades on-line analisadas neste estudo. Presente em apenas duas propostas de atividades on-line, podemos observar sua configuração através do exemplo 5 , a seguir:

Exemplo 5

"Go to our forum, greet your colleagues and introduce yourself.", 17

Atendendo às orientaçôes da proposta de atividade on-line ilustrada pelo exemplo 5 , os alunos praticam a função sociocomunicativa de cumprimentar e se apresentar aos demais participantes do curso. Vale ressaltar que, assim como a videoconferência, o fórum tem seu uso previsto no contexto de ensinoaprendizagem através do AVA Solar, pois ele também está listado nos recursos que otimizam a interação social e a comunicação entre os participantes do processo. Esse tipo de proposta de atividade on-line, ancorada na tecnologia fórum eletrônico, portanto, apresenta relações intrínsecas com o texto escrito e a interação social. A baixa frequência de seu uso, por sua vez, pode ser atribuída às nuances constitutivas da oferta de ensino e de seu objetivo no contexto analisado, qual seja, o da compreensão e produção oral, habilidades que recebem um tratamento secundário quando lidamos com uma tecnologia digital cuja mediação prescreve, predominantemente, a compreensão e a produção escrita.

17 "Vá ao nosso fórum, cumprimente seus colegas e se apresente." 
Ademais, o fórum eletrônico, por si só, não garante seu status como oportunizador da comunicação entre os participantes do processo de ensinoaprendizagem, uma vez que, a depender de seu uso, ele apenas reflete um repositório de opiniōes e sugestões em forma de simples registro linear dentro de uma sequência cronológica, uma estrutura estática com pouca motivação para o intercâmbio de ideias, conforme salienta Primo (2001), sendo que, em alguns casos, eles podem, sim, servir como um ambiente propício ao debate de assuntos propostos por um mediador.

Tendo em vista a continuação e o cumprimento do objetivo de relacionar os recursos digitais predominantemente utilizados nas propostas de atividades on-line com a oferta do ensino da compreensão e produção oral em língua inglesa, faz-se necessário mencionar duas tecnologias digitais que não foram necessariamente utilizadas com o objetivo de promover interação/ comunicação, pertinente à oferta do ensino de língua estrangeira: o gravador, cuja utilização está prevista na realização de quatro propostas de atividades online; e o portfólio, que cumpre a função de repositório para cinco das propostas de atividades on-line desenvolvidas pelos alunos. Vejamos a apresentação dos exemplos 6 e 7 como ilustradores dessa forma de relacionar recurso digital com oferta de proposta de atividade on-line:

Exemplo 6

"Record the following pronouns with the to be and post your recordings in your portfolio. I am. They're. We're. He's. You are. You're. She is. Her. His. Us. Them. Their." ${ }^{18}$

\section{Exemplo 7}

"Portfolio 1. Download the audio file, the questionnaire, and the answer key file. Then listen to the audio, answer the questions then transfer your answers to the answer key file and upload it to your portfolio." ${ }^{19}$

Como podemos observar, a proposta de atividade on-line ilustrada pelo exemplo 6 prevê, inicialmente, a utilização do gravador, para que os alunos

18 "Grave os seguintes pronomes com o verbo ser/estar e poste sua gravação em seu portfólio. Eu sou. Eles são. Nós somos. Ele é. Você é. Vocês são. Ela é. Dela. Dele. Nos. Lhe. Deles."

19 "Portfólio 1. Faça o download do arquivo de áudio, do questionário e do arquivo de respostas. Em seguida escute o áudio, responda às questôes e então transfira suas respostas para o arquivo de respostas e poste-o em seu portfólio." 
possam gravar sua fala ao pronunciar os pronomes pessoais do caso reto seguidos pelo verbo ser/estar, os pronomes pessoais do caso oblíquo e possessivos. Em seguida, demanda, também, a utilização do portfólio, para que os alunos possam postar essa gravação em um espaço no AVA cujo acesso seja possível por parte do professor/tutor da disciplina. O professor/tutor, por sua vez, procede ao acesso, à escuta do áudio e à avaliação do arquivo postado. Já na proposta de atividade on-line ilustrada pelo exemplo 7, a postagem no portfólio que está prevista é de um arquivo de edição de texto com as respostas, através de texto escrito, a um questionário respondido pelos alunos após terem ouvido o áudio que traz as informações necessárias para a realização da proposta de atividade on-line. Assim como os recursos digitais listados anteriormente, o portfólio tem seu uso previsto no contexto de ensino-aprendizagem através do Solar, por estar inserido no elenco de ferramentas constitutivas do próprio AVA. Já o gravador, se não estiver disponível no próprio computador utilizado pelo aluno, necessita ser acessado através de outras páginas da web, sendo que o aluno pode realizar o download desse recurso ou pode proceder à utilização on-line, pois essa tecnologia digital não é constitutiva do Solar. O Solar não é um AVA para a oferta exclusiva do ensino da compreensão e produção oral. No entanto, ele pode ser configurado para esse fim e, juntamente com os outros ambientes virtuais livres das páginas da web, pode se constituir em um espaço virtual de oferta de propostas de atividades on-line que oportunizem a construção do conhecimento através de experiências colaborativas, pois, corroborando Paiva (2010), os usos que os proponentes podem dele fazer permitem sua caracterização com espaço ideal para os alunos se encontrarem com o objetivo de compartilhar, colaborar e aprender juntos.

\section{Considerações finais}

Neste trabalho, apresentei, de maneira exploratória e descritiva (RAUPP; BEUREN, 2004; CELANI, 2005; LEFFA, 2006), um estudo sobre as propostas de atividades on-line para o ensino da compreensão e produção oral em língua inglesa como língua estrangeira. Para isso, foram utilizadas as propostas de atividades on-line praticadas nas disciplinas de compreensão e produção oral da licenciatura semipresencial em Letras/Inglês da UFC, tendo em vista a configuração das propostas de atividades on-line ofertadas para a realização do ensino a distância e suas relaçóes com os recursos digitais que possibilitam a promoção da interação e da comunicação no contexto de $\mathrm{EaD}$. 
O estudo das propostas de atividades on-line se justifica, também, pelo fato de que elas são compreendidas como um dos elementos responsáveis pela orientação e promoção das interações e da comunicação realizadas pelos alunos no ensino de língua estrangeira a distância. Planejadas para serem ancoradas em recursos digitais que medeiam essas interações, é possível observar uma coerência entre o grau de interatividade/comunicação e os objetivos e princípios pedagógicos do processo de ensino-aprendizagem de uma língua estrangeira.

A descrição dos usos dos recursos digitais que constituem a oferta do ensino a distância e sua frequência de utilização, segundo objetivo deste artigo, resultou no catálogo das tecnologias em que os exemplares das propostas de atividades on-line se encontravam ancorados. Essa elaboração, que reflete os recursos digitais utilizados pelos elaboradores do material didático para o ensino da compreensão e produção oral em língua inglesa, justifica-se pela relevância de se refletir sobre a forma como os educadores integram a tecnologia em suas práticas pedagógicas (LANKSHEAR; SNYDER; GREEN, 2000). Os professores de línguas precisam, muitas vezes, elaborar, selecionar e reproduzir conteúdos e propostas de atividades (on-line) que se demonstrem mais coerentes ao ensino comprometido com as situações concretas de uso da língua e, por isso, chamo atenção a cinco aspectos específicos: planejamento; comprometimento; criatividade; formação/capacitação; fluência. É no planejamento que se torna possível prever os comportamentos e as reações que serão desenvolvidos ao longo do processo de ensino-aprendizagem e, a partir dessa previsão, "aparar as arestas" que poderiam estar de encontro com a realização do processo de forma bemsucedida. Para isso, o comprometimento e a criatividade dos proponentes ganham destaque, uma vez que podem ser compreendidos como motivadores de uma oferta que leve em consideração a complexidade do ensino a distância em relação às nuances particulares dos receptores desse produto: é preciso pensar no aluno de língua estrangeira, nas suas condições de recepção, na sua autonomia e, consequentemente, nos usos que ele pode fazer do produto recebido, personalizando-o aos seus interesses e às suas necessidades. Uma sólida formação/ capacitação profissional é o que pode garantir fluência, não apenas do uso da língua estrangeira alvo do ensino, mas também do uso das tecnologias que tornam concretas as possibilidades de esse ensino ser realizado a distância, refletindo proposta comprometida com a formação do cidadão que vive em uma sociedade em que as práticas sociais são mediadas pelas TIC.

Uma vez carente dessa conjuntura que envolve planejamento, comprometimento, criatividade, formação/capacitação e fluência, a proposta de atividade on-line pode apresentar uma configuração que, para se tornar mais 
coerente com os objetivos de ensino e com a modalidade de oferta, necessitaria de maior investimento pedagógico em sua contextualização, por meio do qual possibilitasse maior engajamento do aluno nas açôes previstas em suas orientações. Em alguns casos, parece que o material didático destinado à produção e compreensão das práticas orais em inglês em um curso de $\mathrm{EaD}$ assemelha-se, em alguma medida, a apostilas ou a livros didáticos que, em função das tecnologias em que estão, têm limitações comunicativas. Nesse caso, o ambiente on-line da web, portanto, parece ainda estar longe de ser explorado por quem elabora esse material para cursos on-line.

\section{Referências}

ANPOLL. Lista dos Grupos de Trabalho (GTs). Disponível em: <http:// www.anpoll.org.br/portal/gts/\#>. Acesso em: 19 jul. 2013.

ARAUJO, J. C.; LIMA, S. de C. O papel das propostas de atividades online nas disciplinas semipresenciais de línguas da UFC Virtual. Signum: Estudos da Linguagem, Londrina, v. 14, n. 2, p. 45-60, dez. 2011. Disponível em: <http://www.uel.br/ revistas/uel/index.php/signum/article/view/9290/9663>. Acesso em: 19 jul. 2013.

BELLONI, M. L. Ensaio sobre a educação a distância no Brasil. Educação \& Sociedade, ano XXIII, n. 78, p. 117-142, abr. 2002. Disponível em: <http:// www.scielo.br/pdf/es/v23n78/a08v2378.pdf>. Acesso em: 24 fev. 2012.

BRAGA, D. B.; COSTA, L. A. O computador como instrumento e meio para o ensino/aprendizagem de línguas. Trabalhos em Linguistica Aplicada, Campinas, v. 36, p. 61-79, jul.-dez. 2000. Disponível em: <http://www.iel.unicamp.br/ revista/index.php/tla/article/view/2504/1925>. Acesso em: 19 jul. 2013.

BROWN, H. D. Teaching by Principles: An Interactive Approach to Language Pedagogy. 2. ed. San Francisco: Longman, 2000.

CELANI, M. A. A. Questões de ética na pesquisa em Lingüística Aplicada. Linguagem \& Ensino, Pelotas, v. 8, n. 1, p. 101-122, jan.-jun. 2005.

HARMER, J. How to Teach English: An Introduction to the Practice of English Language Teaching. Harlow: Longman, 1998.

HARMER, J. The Practice of English Language Teaching. 3. ed. Essex: Longman, 2001. LANKSHEAR, C.; SNYDER, I.; GREEN, B. Teachers and Techno-Literacy: Managing Literacy, Technology and Learning in Schools. Saint Leonards: Allen \& Unwin, 2000.

LEFFA, V. J. Aprendizagem de línguas mediada por computador. In:

(Org.). Pesquisa em Lingüistica Aplicada: temas e métodos. Pelotas: Educat, 2006. 
LEFFA, V. J. Malhação na sala de aula: o uso do exercício no ensino de línguas. Revista Brasileira de Linguistica Aplicada, Belo Horizonte, v. 8, n. 1, p. 139-158, 2008. Disponível em: <http://www.scielo.br/pdf/rbla/v8n1/07.pdf>. Acesso em: 19 jul. 2013.

LIMA, S. C. Atividades on-line mediadoras da familiarização com as potencialidades de interatividade da web. Hipertextus, Recife, n. 5, ago. 2010a. Disponível em: <http://www.hipertextus.net/volume5/Samuel-de-Carvalho-Lima.pdf>. Acesso em: 19 jul. 2013. Não paginado.

LIMA, S. C. Ensino de língua inglesa em ambiente virtual: atividades e letramentos. In: CONGRESSO INTERNACIONAL DA ABRALIN, 7., 2011, Curitiba. Anais... Curitiba: Abralin, 2011. v. 1, p. 3923-3930.

LIMA, S. C. Ensino de línguas mediado por computador: um estudo das propostas de atividades online para o ensino da compreensão e produção oral em língua inglesa. 2012. 139 f. Tese (Doutorado em Linguística) - Programa de PósGraduação em Linguística, Universidade Federal do Ceará, Fortaleza, 2012.

LIMA, S. C. Letramento digital e atividades on-line de comunicação. Educação \& Tecnologia, Belo Horizonte, v. 15, n. 1, p. 23-36, 2010 b.

LIMA, S. C. Letramentos e atividades on-line em Ambiente Virtual de Aprendizagem. 2009. 124 f. Dissertação (Mestrado em Linguística) - Programa de PósGraduação em Linguística, Universidade Federal do Ceará, Fortaleza, 2009.

LIMA, S. C. Potential Relationship between Digital Literacy and E-tivities in English Language Teaching. In: SHAFAEI, A. (Org.). Frontiers of Language and Teaching: Proceedings of the 2010 International Online Language Conference (IOLC 2010). Boca Raton: Universal, 2010c. p. 236-243.

LIMA, S. C.; ARAUJO, J. C. Letramento digital em ambiente virtual de aprendizagem: descrição das práticas de leitura e escrita promovidas por propostas de atividades no curso de Letras/Inglês. In: ARAÚJO, J. C.; DIEB, M.; LIMA, S. C. (Org.). Línguas na web: links entre ensino e aprendizagem. Ijuí: Editora Unijuí, 2010. p. 243-266.

LIMA, S. C.; ARAUJO, J. C. Relaçôes entre letramento digital e atividades online no processo de ensino-aprendizagem de lingual maternal em ambientes virtuais. In: GONÇALVES, A. V.; PINHEIRO, A. S. (Org.). Nas trilhas do letramento: entre teoria, prática e formação docente. São Paulo: Mercado de Letras, 2011. p. 159-204.

LIMA, S. C.; ARAUJO, J. C.; DIEB, M. Teaching Academic Genres in Digital Contexts. In: SHAFAEI, A. (Org.). Frontiers of Language and Teaching. Boca Raton: Universal, 2011. v. 2, p. 46-51. 
MOITA LOPES, L. P. Contextos institucionais em Linguística Aplicada: novos rumos. Intercâmbio, São Paulo, v. 5, p. 3-14, 1996. Disponível em: <http:// revistas.pucsp.br/index.php/intercambio/article/view/4107/2753>. Acesso em: 19 jul. 2013.

MORAN, J. M. Como utilizar a internet na educação. Ciência da Informação, Brasília, v. 26, n. 2, maio-ago. 1997. Disponível em: <http://www.scielo.br/ scielo.php?pid=S0100-19651997000200006\&script=sci_arttext\&tlng=es $>$ Acesso em: 24 fev. 2012.

PAIVA, V. L. M. O. Ambientes virtuais de aprendizagem: implicações epistemológicas. Educação em Revista, Belo Horizonte, v. 26, n. 03, p.353-370, dez. 2010. Disponível em: <http://www.scielo.br/pdf/edur/v26n3/v26n3a18.pdf>. Acesso em: 20 fev. 2012.

PAIVA, V. L. M. O. O uso da tecnologia no ensino de linguas estrangeiras: breve retrospectiva histórica. No prelo. Disponível em: <http://www.veramenezes.com/ techist.pdf>. Acesso em: 19 nov. 2011.

PEREIRA, E. C.; ARAÚJO, J. C. Interação em ambientes virtuais de aprendizagem: a preservação de faces em fóruns eletrônicos. In: LEUQUIN, E. V. L. F.; SOARES, M. E.; BEZERRA, J. R. M. (Org.). Gênero, ensino e formação de professores. São Paulo: Mercado de Letras, 2011. p. 57-70.

PRIMO, A. F. T. Ferramentas de interação em ambientes educacionais mediados por computador. Educação, Porto Alegre, v. XXIV, n. 44, p. 127-149, 2001. Disponível em: <http:/www.nuted.ufrgs.br/oficinas/interacao/ferramentas_ interacao.pdf> Acesso em: 4 nov. 2012.

RAUPP, F. M.; BEUREN, I. M. Metodologia da pesquisa aplicável às ciências sociais. In: BEUREN, I. M. (Org.). Como elaborar trabalhos monográficos em contabilidade: teoria e prática. 2. ed. São Paulo: Atlas, 2004.

SALMON, G. E-tivities: The Key to Active Learning. London: Kogan Page, 2002. SILVA, F. M. Chats e e-fóruns na EaD virtual: links entre mediação pedagógica e hipertextualidade. 2008. 187 f. Dissertação (Mestrado em Linguística) Programa de Pós-Graduação em Linguística, Universidade Federal do Ceará, Fortaleza, 2008.

SNYDER, I. Ame-os ou deixe-os: navegando no panorama de letramentos em tempos digitais. In: ARAÚJO, J. C.; DIEB, M. (Org.). Letramentos na web: gêneros, interação e ensino. Fortaleza: Edições UFC, 2009.

Recebido em 07/12/2012. Aprovado em 09/05/2013. 